\title{
Proteoglycan Isolated from Phellinus linteus Induces Toll-Like Receptors 2- and 4-Mediated Maturation of Murine Dendritic Cells via Activation of ERK, p38, and NF- $K B$
}

\author{
Gi-Young KIM, ${ }^{a}$ Myung-Geum HAN ${ }^{b}$ Yung-Sun Song, ${ }^{b}$ Byung-Cheul SHIN, ${ }^{b}$ Yong-Il SHIN, ${ }^{c}$ \\ Hee-Jeong LeE, ${ }^{a}$ Dong-Oh Moon, ${ }^{a}$ Chang-Min LeE, ${ }^{a}$ Jong-Young KwAK, ${ }^{d, e}$ Yoe-Sik BAE, ${ }^{d, e}$ \\ Jae-Dong LeE, ${ }^{f}$ and Yeong-Min PARK ${ }^{*}, a$ \\ ${ }^{a}$ Deparmtment of Microbiology and Medical Research Institute, Pusan National University College of Medicine; Pusan \\ 602-739, South Korea: ${ }^{b}$ Department of Oriental Rehabilitation Medicine, College of Oriental Medicine, Wonkwang \\ University; ' Department of Rehabilitation Medicine, College of Medicine, Wonkwang University; Iksan city 570-180, \\ Jeonbuk, South Korea: ${ }^{d}$ Department of Biochemistry, Dong-A University College of Medidine ${ }^{e}$ Medical Research Center \\ for Cancer Molecular Therapy; Dong-A University College of Medicine; Pusan 602-723, Republic of Korea: and \\ ${ }^{f}$ Department of Microbiology, College of Natural Sciences, Pusan National University; Pusan 602-739, South Korea. \\ Received April 28, 2004; accepted July 12, 2004
}

\begin{abstract}
Mushroom polysaccharides are increasingly being utilized to treat a wide variety of diseases. Phellinus linteus proteoglycan (PL) has been reported to have anti-tumor and immunomodulatory properties. However, the cellular and molecular mechanism underlying its therapeutic effect is poorly understood. In this study, we investigated whether PL induces the phenotypic and functional maturation of murine bone marrow-derived dendritic cells (DC) and the possibility that Toll-like receptors (TLRs), which are known to be involved in immune-related responses, may be the receptor(s) of PL. The expression of surface molecules, including major histocompatibility complex (MHC) class II and CD86, increased on DC that were stimulated in a dose-dependent manner with PL, in comparison with unstimulated DC. Furthermore, PL increases the production of IL-12 by DC, as well as the IL-2 secretion and proliferation of allogeneic T cells. In addition, the activities of PL on DC were significantly reduced by treating the cells with anti-TLR2 or anti-TLR4 antibody (Ab) prior to PL, suggesting that both of them are possible receptors of PL. Also, maturation of DC by PL was able to directly activate mitogen-activated protein kinases (MAPKs), such as ERK1/2 and p38, and the nuclear transcription factor NF- $\kappa$ B p65. Also, the pretreatment of DC with inhibitors of NF- $K B$ p65, and ERK and p38 MAPK signal pathways inhibited PL-induced up-regulation of surface molecules, such as MHC class II and CD86, and IL-12 production. Our results demonstrated that PL stimulation could induce the phenotypic and functional maturation of DC via TLR2 and/or TLR4 mediated-NF- $\kappa$ B, ERK and p38 MAPK signal pathways.
\end{abstract}

Key words Phellinus linteus; proteoglycan; dendritic cell; Toll-like receptor; mitogen-activated protein kinase

Dendritic cells (DC) are the most potent antigen-presenting cells (APCs). Immature DC reside in peripheral tissues effectively capture and process exogenous protein and migrate to peripheral lymphoid tissues. After the uptake of antigen and exposure to inflammatory agents, DC undergo a process of maturation such that they have a greatly diminished capacity for antigen uptake and processing. ${ }^{1-4)}$ The maturing DC migrate to lymphoid organs, where they stimulate naive $\mathrm{T}$ cells through the signals of both major histocompatability complex (MHC) molecules presenting antigenpeptides and costimulatory molecules. ${ }^{5,6} \mathrm{DC}$ are also highly responsive to inflammatory cytokines, such as tumor necrosis factor (TNF)- $\alpha$, or bacterial products, such as lipopolysaccharide (LPS), encountered in peripheral organs, which induce a series of phenotypic and functional changes in DC. ${ }^{7,8)}$ Similar changes indicative of maturation have also been reported following infection with mycoplasma, viruses, intracellular bacteria, and parasites. ${ }^{9-11)}$ In addition to, $\beta$-glucan and mushroom polysaccharides, known as immunomodulators, induce regulatory effects on maturation and function of DC. ${ }^{12,13)}$ These phenotypic changes parallel the functional transition of DC from Ag-capturing cells to APCs.

Recognition of pathogens is mediated by a set of germlineencoded receptors that are referred to as pattern-recognition receptors (PRRs). These receptors recognize conserved mol- ecular patterns that are shared by large groups of microorganisms. Toll-like receptors (TLRs) function as the PRRs in mammals and play an essential role in the recognition of microbial components. ${ }^{14)}$ The TLRs may also recognize endogenous ligands induced during innate immuneresponses. TLRs are type I transmembrane proteins that are evolutionarily conserved between insects and humans. ${ }^{15)}$ Toll was first identified as an essential molecule for embryonic patterning in Drosophila and was subsequently shown to be key in antifungal immunity. ${ }^{16)}$ Of the 10 TLRs discovered to date, TLR2 is activated primarily by lipoproteins and glycolipids, ${ }^{17-20)}$ TLR4 is predominantly activated by LPS and lipoteichoic acid, ${ }^{21,22)}$ TLR5 recognizes flagella from outer membrane of Gram-negative bacteria, ${ }^{23)}$ and TLR9 firstly recognizes CpG DNA. ${ }^{24,25)}$ Recent studies showed that TLR2 and TLR4, which are the signaling components of LPS and consequently trigger its cellular transduction, led to NF- $\kappa \mathrm{B}$ activation and DC maturation. ${ }^{25-27)}$ The adjuvant activity of bacterial products is important not only for antibacterial responses induced by peripheral DC but also for vaccine development. However, LPS is excluded because of its high toxicity, as it is one of the main causes of septic shock in humans. ${ }^{28)}$

It has not been reported yet whether TLR signaling can be activated by polysaccharides isolated from naturally occur- 
ring mushrooms, although workers in the biomedical field have studied many mushroom-derived polysaccharides. Especially, we previously reported that proteoglycan (PL) isolated from Phellinus linteus was previously shown to increase lymphocyte proliferation, T-dependent antibody responses and macrophage activation. ${ }^{29-31)}$ Furthermore, proteoglycan significantly inhibited the metastasis and growth of B16 melanoma cells and prolonged the survival time of tumor-bearing mice. ${ }^{32)}$ However, the cellular and molecular mechanism underlying its therapeutic effect is poorly understood. Furthermore, we investigated whether PL induces the phenotypic and functional maturation of DC and the possibility that TLRs, which are known to be involved in immunerelated responses, may be the receptor(s) of PL. We have shown for the first time PL activating the phenotypic and functional maturation of DC the activation of ERK1/2 and p38 MAPK mediated TLRs in DC. Also, PL was observed increasing the nuclear translocation of NF- $\kappa \mathrm{B}$ p 65 .

\section{MATERIALS AND METHODS}

Animals and Preparation of PL Male 8- to 12-wk-old C57BL/6 $\left(\mathrm{H}-2 \mathrm{~K}^{\mathrm{b}}\right.$ and $\left.\mathrm{I}-\mathrm{A}^{\mathrm{b}}\right)$ and BALB/c $\left(\mathrm{H}-2 \mathrm{~K}^{\mathrm{d}}\right.$ and $\left.\mathrm{I}-\mathrm{A}^{\mathrm{d}}\right)$ mice were purchased from the Korean Institute of Chemistry Technology (Daejeon, Korea). They were housed in specific pathogen-free enclosures in our animal facility for at least 1 week before use. Basic characteristic analyses of PL were reported in our previous study. ${ }^{33)}$

Generation of Murine Bone Marrow (BM)-Derived Myeloid DC BM-derived myeloid DC were generated as described previously in detail, ${ }^{34)}$ with minor modification. Briefly, bone marrow cells from the femura and tibiae of C57BL/6 mice were flushed and depleted of red blood cell (RBC) by hypotonic lysis using RBC lysing buffer (Sigma). Cells were grown from precursors at a starting concentration of $1 \times 10^{6}$ cells $/ \mathrm{ml}$ in RPMI 1640 , supplemented with $10 \%$ $\mathrm{v} / \mathrm{v}$ heat-inactivated FBS, L-glutamine, nonessential amino acids, sodium pyruvate, penicillin-streptomycin, HEPES, 2-ME (all from Sigma) for $3 \mathrm{~h}$ and then non-adherent cells were washed out. Twenty $\mathrm{ng} / \mathrm{ml} \mathrm{rmGM-CSF}$ and $20 \mathrm{ng} / \mathrm{ml}$ IL-4 were given to the culture medium referred to subsequently as complete medium. In parallel experiment, either PL $(10,50$, or $100 \mu \mathrm{g} / \mathrm{ml})$, or LPS (serotype 0111:24; Sigma) as a positive control was added to the culture medium on day 5. On day 6 of culture, non-adherent and loosely adherent cells were collected as BM-derived myeloid. The cells were mainly composed of $\mathrm{CD}_{11 \mathrm{c}^{+}}$cells $\left(>85 \%\right.$ : $\mathrm{CD}^{+} ; 5 \%$ : $\left.\mathrm{CD} 19^{+} ; 3 \%\right)$ when determined by staining with fluoresecin isothiocyanate (FITC)-conjugated anti-C11c antibody (PharMingen).

Flow Cytometric Analysis On day 6, BM-derived DC were harvested, washed with PBS, and resuspended in ice cold FACS washing buffer (2\% FBS and $0.1 \%$ sodium azide in PBS). Cells were first blocked with $10 \% \mathrm{v} / \mathrm{v}$ normal goat serum for $15 \mathrm{~min}$ at $4{ }^{\circ} \mathrm{C}$ and stained with phycoerythrin (PE)-conjugated anti-I-A ${ }^{\mathrm{b}}$ (MHC class II) and anti-CD86 with FITC-conjugated anti-CD11c antibody (Pharmingen, SanDiego, CA, U.S.A.) for $30 \mathrm{~min}$ at $4{ }^{\circ} \mathrm{C}$. In parallel experiment, neutralizing antibodies (Santa Cruz, CA, U.S.A.) to surface receptors were used for investigating the receptor. Stained cells were analyzed using a FACSCalibur flow cytometer (Becton Dickinson, San Jose, CA, U.S.A.).

Cytokine Assay Cells were first blocked with 10\% v/v normal goat serum for $15 \mathrm{~min}$ at $4{ }^{\circ} \mathrm{C}$ and then stained with FITC-conjugated CD11c antibody for $30 \mathrm{~min}$ at $4{ }^{\circ} \mathrm{C}$. Cells stained with the appropriate isotype-matched Ig were used as negative controls. The cells were fixed and permeated with the Cytofix/Cytoperm kit (PharMingen) according to the manufacturer's instructions. Intracellular IL-12p40/p70 was stained with fluorescein R-phycoerythrin (PE)-conjugated antibodies (PharMingen) in a permeation buffer. The cells were analyzed on a FACSCalibur flow cytometer with the CellQuest program. Furthermore, IL-12p70 from DC was measured using an ELISA kit (PharMingen) according to the manufacturer's instructions. The detection limits for IL$12 \mathrm{p} 70$ was $7.8 \mathrm{pg} / \mathrm{ml}$.

Endocytosis Assay To analysis endocytosis of DC, $1 \times 10^{5}$ cells were incubated at $37^{\circ} \mathrm{C}$ for $1 \mathrm{~h}$ with $1 \mathrm{mg} / \mathrm{ml}$ dextran-FITC (42000 Da; Sigma). After incubation, cells were washed twice with cold HBSS and stained using the PE-conjugated anti-CD11c antibody (PharMingen). Double stained DC were analyzed by a FACSCalibur flow cytometer. In addition, the parallel experiments were performed at $4{ }^{\circ} \mathrm{C}$ to show that the uptake of dextran by BM-derived DC is inhibited at low temperatures.

Mixed Lymphocyte Reaction (MLR) Induced by DC Responder $\mathrm{T}$ cells used for the allogeneic $\mathrm{T}$-cell reaction were isolated by MACS column (Miltenyi Biotec, Germany) passing through mononuclear cells from BALB/c mice. They were mainly composed of $\mathrm{CD}^{+}$cells $(>93 \%)$ when determined by staining with FITC-conjugated anti-CD3 antibody (PharMingen). BM-derived DC were treated with $50 \mu \mathrm{g} / \mathrm{ml}$ mitomycin $\mathrm{C}$ (Sigma) for $1 \mathrm{~h}$ and added in graded doses to $1 \times 10^{5}$ allogeneic $\mathrm{T}$ cells in U-bottom 96-well microtiter culture plates. Cell proliferation during the last $18 \mathrm{~h}$ of $72 \mathrm{~h}$ culture was quantified by $\left[{ }^{3} \mathrm{H}\right]$ thymidine (NEN-DuPont, Boston, MA, U.S.A.) uptake of cells incubated with $0.5 \mu \mathrm{Ci}$ of [methyl- $\left.{ }^{3} \mathrm{H}\right]$ thymidine (NEN-DuPont). The cells were harvested onto glass fibre filters (Inotech Biosystems, Zurich, Switzerland), and the radioactivity was measured in a scintillation counter. Results are presented as mean c.p.m. of triplicated cultures.

Assessment of ERK and p38 Kinase Activation by Western Blotting The cells were exposed to LPS or PL and following $15 \mathrm{~min}$ of incubation at $37^{\circ} \mathrm{C}$, cells were washed twice with cold PBS and lysed with modified RIPA buffer $(1.0 \%$ NP-40, $1.0 \%$ sodium deoxycholate, $150 \mathrm{~nm}$ $\mathrm{NaCl}, 10 \mathrm{~mm}$ Tris- $\mathrm{HCl}$ [pH 7.5], 5.0 mm sodium pyrophosphate, $1.0 \mathrm{~mm} \mathrm{NaVO}_{4}, 5.0 \mathrm{~mm} \mathrm{NaF}, 1.0 \mu \mathrm{g} / \mathrm{ml}$ leupeptin, and $0.1 \mathrm{~mm}$ phenylmethylsulfonyl fluoride) for $15 \mathrm{~min}$ at $4{ }^{\circ} \mathrm{C}$. Lysates were cleared by centrifugation at $14000 \times \boldsymbol{g}$ for $20 \mathrm{~min} 4{ }^{\circ} \mathrm{C}$. Protein content of cell lysates was determined using the Micro BCA assay kit (Pierce, Rockford, IL, U.S.A.). Equivalent amounts of proteins were separated by SDS-10\% PAGE and analyzed by Western blotting using an anti-phospho-ERK (Santa Cruz, CA, U.S.A.) or anti-phospho-p38 (Santa Cruz, CA, U.S.A.) MAP kinase mAb for $1 \mathrm{~h}$ as described by the manufacturer of the antibodies. Following washing three times with TBST, membranes were incubated with secondary HRP-conjugated anti-mouse IgG for $1 \mathrm{~h}$. After washing for $10 \mathrm{~min}$ four times, the blots were developed using the ECL system (Amersham) by following the 
manufacturer's instructions.

Preparation of Nuclear Extracts and Assessment of NF- $\kappa$ B Activation by Western Blotting DC nuclear extracts were prepared using NE-PER nuclear and cytoplasmic extraction reagents (Pierce, Rockford, IL, U.S.A.), is according to the manufacturer's instructions. NF- $\kappa \mathrm{B}$ p 65 subunits in the nuclear extracts were determined by Western blot analysis with anti-NF- $\kappa$ B p65 subunit Ab (Santa Cruz, CA, U.S.A.).

Statistics The results were expressed as the mean \pm S.D. of the indicated number of experiments. The statistical significance was estimated using a Student's $t$-test for unpaired observations. A $p$ value of $<0.05$ was considered to be significant.

\section{RESULTS}

PL Induces Maturation of Bone Marrow (BM)-Derived
DC in a Dose-Dependent and TLR2 and 4-Mediated Manner We investigated whether PL isolated from $P$. linteus was able to induce the maturation of BM-DC. Stimulation of DC with 10,50 , and $100 \mu \mathrm{g} / \mathrm{ml} \mathrm{PL}$ for $24 \mathrm{~h}$ resulted in a dose-dependent up-regulation of the costimulatory molecules CD86 and MHC class II molecules and thereby phenotypic maturation of DC (Fig. 1A). Figure 1B (thick lines) shows that PL, similar to LPS, induced dramatic up-regulation of CD86 and MHC class II on the surface of CD11 $\mathrm{c}^{+}$ DC. The up-regulation of these molecules was observed just after $6 \mathrm{~h}$ of stimulation and was not due to LPS contamination in the PL preparation, since PL did not show any effect in the presence of polymyxin B (PB, thin lines) or LPS inhibitors. $\mathrm{PB}$ effectively inhibited the surface expression of CD86 and MHC class II. Inhibitory effect of PB was increased by LPS, but it had no effect on untreated- and PLtreated DC.

Additionally, to assess whether PL-induced maturation of
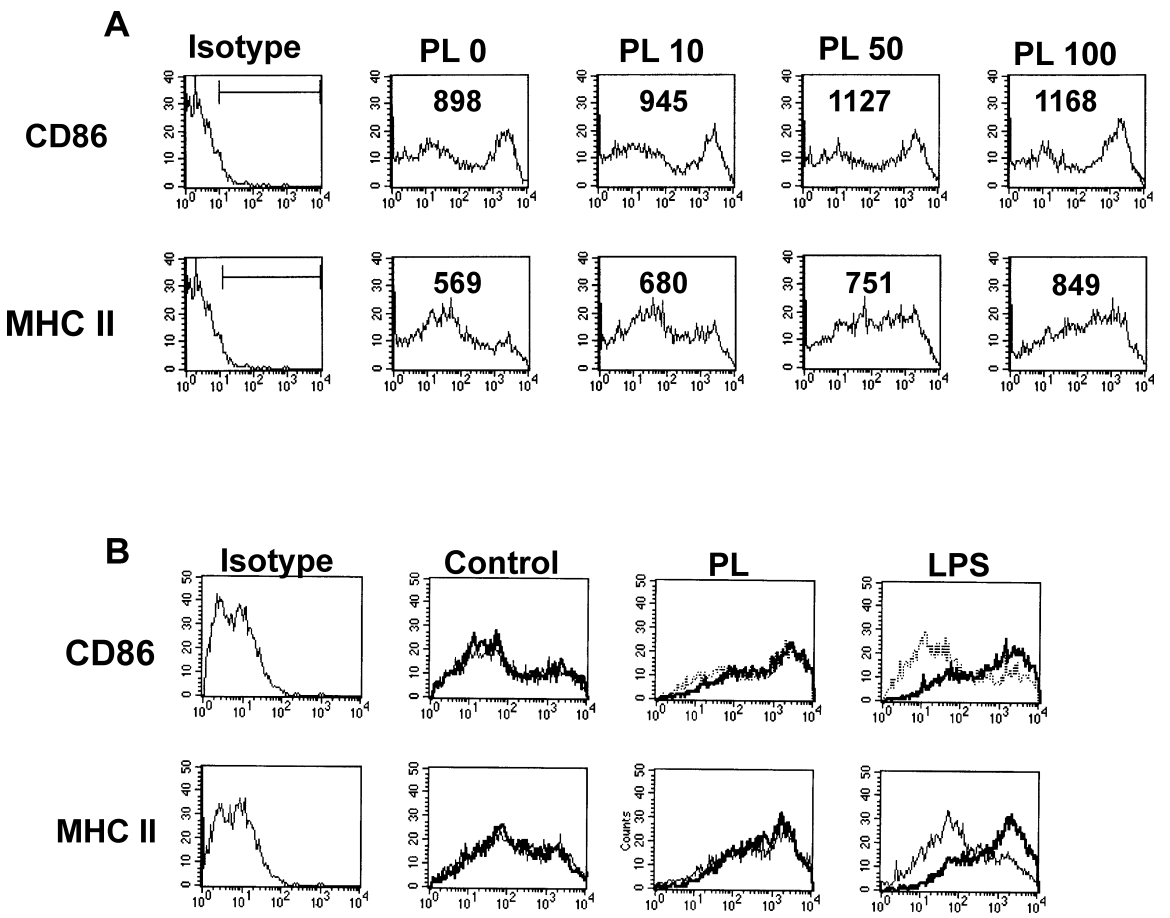

Fig. 1. PL Induces the Up-Regulation of CD86 and MHC Class II in a Dose-Dependent Manner during DC Maturation

DC were generated as described in Materials and Methods. At day 6, cells were harvested and analyzed by two-color flow cytometry. Cells were gated on CD11 $\mathrm{c}^{+}$. PL was added at concentrations of $0,10,50$, or $100 \mu \mathrm{g} / \mathrm{ml}$ to DC for $24 \mathrm{~h}$ and analyzed the expression of CD86 and MHC class II (A). DC were left untreated (control) or were stimulated for $24 \mathrm{~h}$ with $100 \mu \mathrm{g} / \mathrm{ml}$ PL or $100 \mathrm{ng} / \mathrm{ml}$ LPS on day 5 in the absence (LPS; thick lines; CD86, 1353 \pm 89 ; MHC II, 958 \pm 56 ) or presence (LPS; thin lines; CD86, 682 \pm 56 ; MHC II, $579 \pm 34$ ) of polymyxin $B(B)$. The histogram is from one representative experiment out of 3 performed.

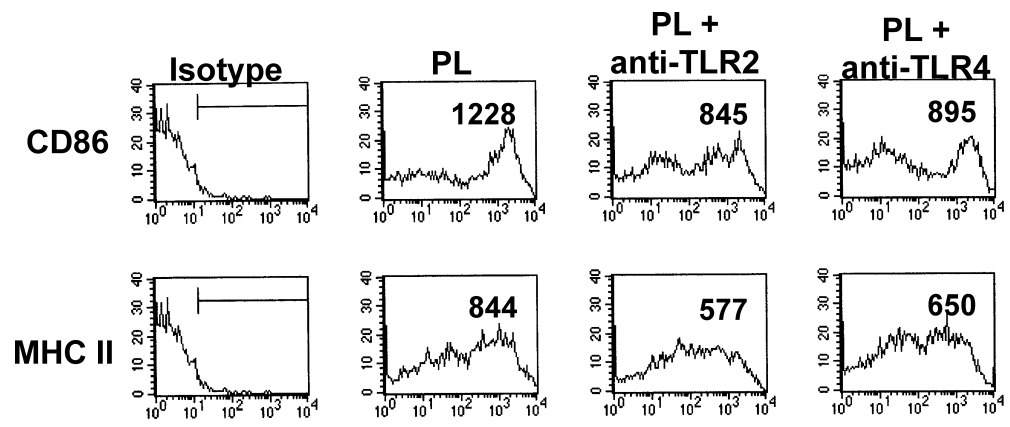

Fig. 2. DC Stimulated with PL are Impaired in the Up-Regulation of CD86 and MHC Class II in the Presence of Anti-TLR2 or Anti-TLR4 Ab

DC were preincubated for 30 min with the indicated $\mathrm{Ab}$ and then incubated with PL for an additional $24 \mathrm{~h}$. Cells were gated on CD11 ${ }^{+}$, and then the levels of CD86 and MHC class II were determined by flow cytometry. The histogram is from one representative experiment out of 3 performed. 
A
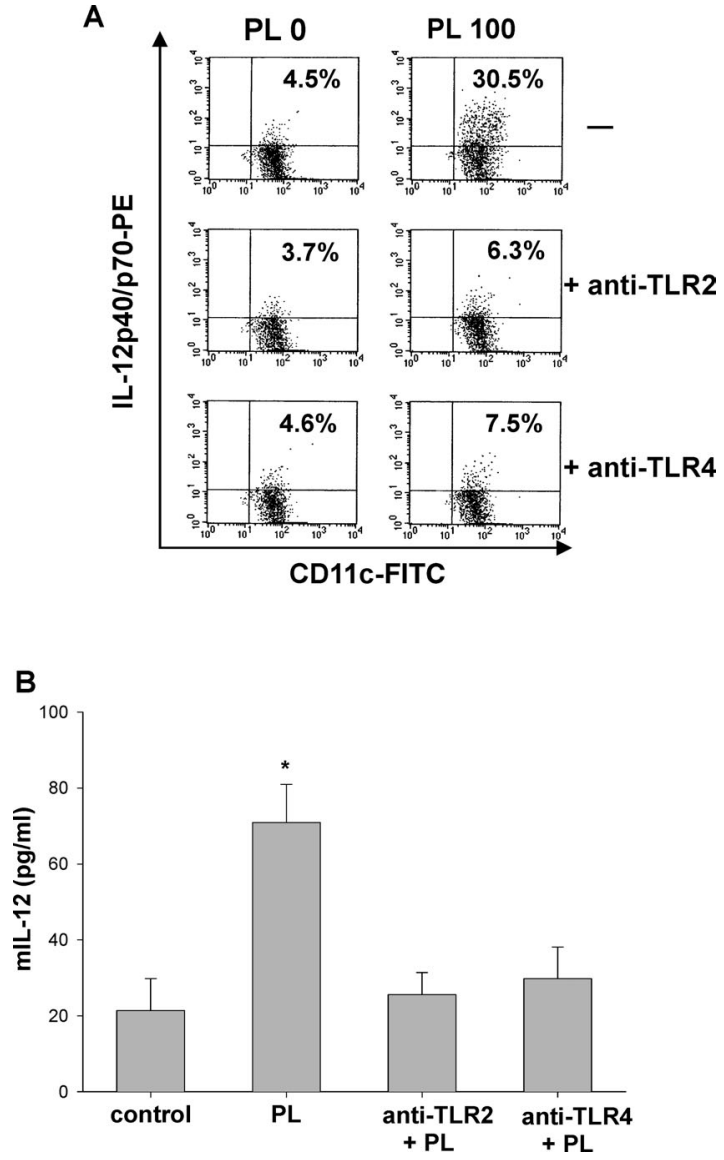

Fig. 3. PL Induces IL-12 Production in DC through TLR2 and/or 4

BM-DC were stimulated by PL $(100 \mu \mathrm{g} / \mathrm{ml})$ for $24 \mathrm{~h}$ and IL-12p $40 / \mathrm{p} 70$ expression in $\mathrm{CD} 11 \mathrm{c}^{+} \mathrm{DC}$ was subsequently analyzed by intracellular cytokine staining (A). BM-DC $\left(5 \times 10^{5} \mathrm{cell} \mathrm{s} / \mathrm{ml}\right)$ for $24 \mathrm{~h}$ were cultured, and bioactive IL-12p70 production was analyzed using ELISA from culture supernatants (B). The data represents the means $( \pm$ S.D.) of 3 separate experiments.

DC was initiated through TLR2 and TLR4, we examined the effects of anti-TLR2 and anti-TLR4 Ab treatment on PL-induced phenotypic maturation of DC to further characterize the membrane receptor of PL. As shown in Fig. 2, anti-TLR2 and anti-TLR4 significantly decreased the PL-induced CD86 and MHC class II expression. Also, expression of CD86 and MHC class II in response to LPS was upregulated in BM-DC treated with anti-TLR2 Ab, but not anti-TLR4 Ab (data not shown). Therefore, these observations indicate that PL increases the costimulatory molecules CD86 and MHC class II molecules on DC through TLR2 and TLR4 signaling pathway.

PL Increases Intracellular and Bioactive IL-12 Secretion, But Not IL-10 from DC IL-12 production is also a functionally important marker for DC maturation and can be used as a method for selecting Th1-inducing adjuvant. As shown in Fig. 3A, intracellular staining of FITC-labeled CD11 ${ }^{+}$DC with PE-labeled IL-12p40/p70 mAb revealed that PL-treated DC $(100 \mu \mathrm{g} / \mathrm{ml})$ expressed higher amounts of IL-12 p40/p70 compared with untreated DC, whereas IL-10 was little affected (data not shown). Whereas stimulation of DC with PL resulted in a response of IL-12p40/p70; preincubation of anti-TLR2 or anti-TLR4 $\mathrm{Ab}$ for $1 \mathrm{~h}$ led to an impaired response of IL-12p40/p70. Also, we analyzed the secretion of bioactive IL-12p70 by PL- or LPS-treated DC

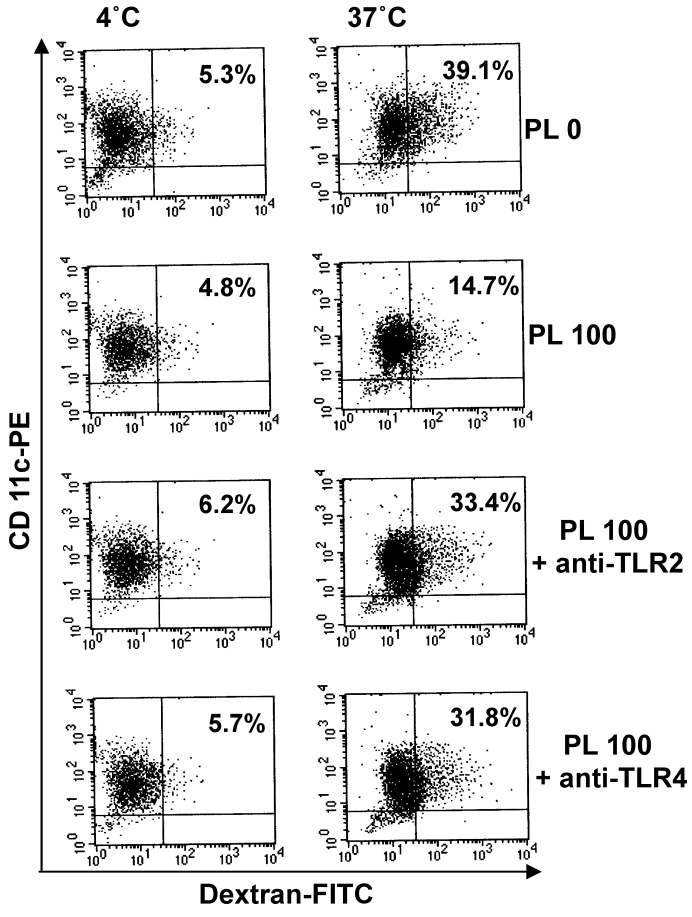

Fig. 4. The Ag Uptake of DC Stimulated with PL Is Decreased through TLR2 and/or 4

DC $\left(1 \times 10^{5}\right.$ cells $)$ were treated either with $100 \mu \mathrm{g} / \mathrm{ml}$ PL in the absence or presence of anti-TLR 2 or anti-TLR $4 \mathrm{Ab}(5 \mu \mathrm{g} / \mathrm{ml})$ for $24 \mathrm{~h}$. The endocytic activity of the DC was determined by flow cytometer after treatment with dextran-FITC. Thereafter, the cells were washed twice with cold HBSS and stained using the PE-conjugated anti-CD11c antibody. The control endocytic activity was determined after dextran-FITC treatment at $4{ }^{\circ} \mathrm{C}$. The numbers represent the percentages of cells. To confirm the results, we repeated these experiment 3 times.

(Fig. 3). When supernatants where analyzed by ELISA (detection limit, $7.8 \mathrm{pg} / \mathrm{ml})$, IL-10 was also not detectable after PL stimulation (data now shown). The DC control group secreted a low concentration of IL-12p70 (21.4 $5.1 \mathrm{pg} / \mathrm{ml})$; DC stimulated with PL secreted higher concentrations of IL$12 \mathrm{p} 70(70.9 \pm 10.1 \mathrm{pg} / \mathrm{ml})$. LPS-treated DC as positive control produced high level of IL-12p70 $(98.3 \pm 15.3 \mathrm{pg} / \mathrm{ml})$. Enhanced secretions of IL-12p70 in PL-stimulated DC were dramatically decreased by the preincubation of anti-TLR2 $(26.5 \pm 8.3 \mathrm{pg} / \mathrm{ml})$ or anti-TLR4 $(29.8 \pm 4.7 \mathrm{pg} / \mathrm{ml}) \mathrm{Ab}$.

Importantly, stimulation with PL markedly enhanced intracellular IL-12 p40/p70 production by the DC control, indicating that exposure to PL enhanced the capability of DC to produce high amounts of bioactive IL-12p70 through TLR2 and/or TLR4 signal pathway.

PL-Treated DC are Functionally Active with Low Endocytic Capacity The phenotypic analysis and IL-12 production indicated that exposure to PL profoundly enhanced the maturation of in vitro-generated myeloid DC. As it is well known that immature DC lose their capability to endocytose in the process of maturation, ${ }^{1,2}$ we also examined whether PL-treated DC still possess an ability to endocytose or whether this property is lost after treatment. Untreated and PL-treated DC were incubated with dextran-FITC for $1 \mathrm{~h}$ at 4 and $37^{\circ} \mathrm{C}$, and examined by flow cytometric analysis to determine the percentage of DC taking it up, and to quantitate the uptake by endocytosis. Control experiments for the potential nonspecific association of dextran-FITC with DC were set up in parallel at $4{ }^{\circ} \mathrm{C}$. DC in the absence of PL stim- 

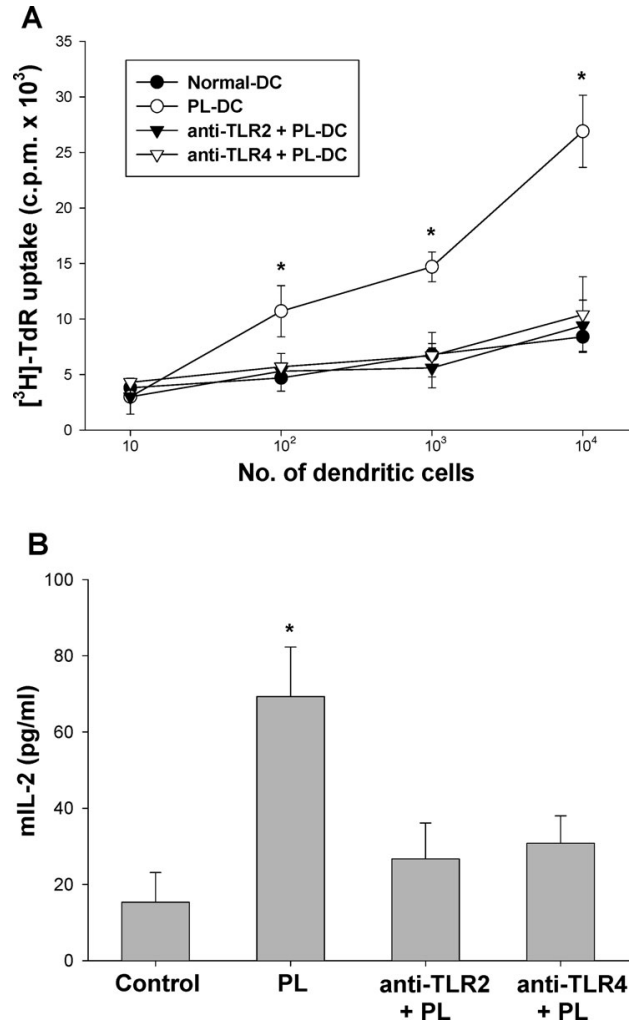

Fig. 5. PL Increases the Proliferation of Allogeneic T Cells and IL-2 Production through Maturation of DC

DC were cultured in medium with or without $100 \mu \mathrm{g} / \mathrm{ml} \mathrm{PL}$ for $24 \mathrm{~h}$. The treated DC were harvested and washed extensively to remove PL. An MLR was conducted for $5 \mathrm{~d}$ as described in Materials and Methods. A background level of $\left[{ }^{3} \mathrm{H}\right] \mathrm{TdR}$ uptake was determined by measuring reactions without stimulators (A). Analysis of IL-2 levels in $48 \mathrm{~h}$ MLR supernatants (stimulator-responder ration, 0.1 ) by ELISA (B). The values are the mean of triplicate \pm S.D. Similar results were obtained in 3 separate experiments.

ulation were quite efficient in the internalization of dextranFITC (Fig. 4). PL-treated DC had a substantially diminished endocytic capacity, indicating that PL induced DC maturation. PL was, therefore, an efficient inducer for DC maturation via TLR-2 and/or TLR4-signal pathway.

PL Enhances the Allogeneic T-Cell Stimulation by DC The increased expression in surface markers involved in the presentation of antigen to $\mathrm{T}$ cells as observed in PL-treated DC suggests that PL can induce them to play a better role as stimulator cells in allogeneic T-cell responses. To test this possibility, DC were treated with PL, washed thoroughly after $24 \mathrm{~h}$, and variable numbers of PL-treated DC were incubated for $5 \mathrm{~d}$ with a fixed number of partially purified allogeneic T cells. As shown in Fig. 5, PL-treated DC could have 5-10-fold more potent $\mathrm{T}$ cell stimulators than untreated DC (Fig. 5A). These effects were completely blocked by preincubation with anti-TLR 2 or $4 \mathrm{Ab}$. Additionally, T cell activation was assessed by IL-2 release. Because DC did not produce IL-2, activated $\mathrm{T}$ cells in the cocultures were the only source of IL-2. DC stimulated with PL induced IL-2 secretions from $\mathrm{T}$ cells, whereas $\mathrm{DC}$, in the pretreatment of antiTLR2 or anti-TLR4 Ab, stimulated with PL did not induce inhibited IL-2 secretions of T cells (Fig. 5B). These results, therefore, suggest that the activation and maturation of $\mathrm{DC}$ by PL might be crucial for functioning as potent stimulatory cells via TLR2 and/or TLR4 in inducing primary T-cell immune responses.
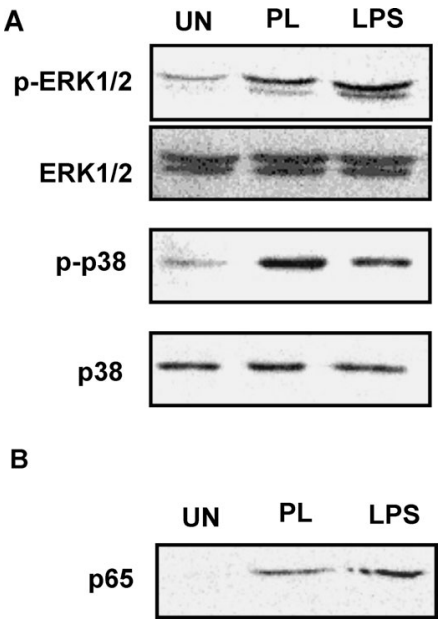

Fig. 6. PL Increases the Activation of Mitogen-Activated Protein Kinases (MAPKs) and the Translocalization of p65

DC were treated with $100 \mu \mathrm{g} / \mathrm{ml}$ of PL or $100 \mathrm{ng} / \mathrm{ml}$ of LPS for $20 \mathrm{~min}$. Cell lysates were prepared and blotted with anti-phospho-ERK1/2 (p-p44/42), anti-ERK1/2 (p44/42), anti-phospho-p38 (p-p38), and anti-p38 (p38) antibodies (A). DC were treated with PL for $30 \mathrm{~min}$ for Western blot (B). The bound antibody was visualized with biotinylated goat anti-rabbit IgG. The results shown were representative of three independent experiments. UN represents the chemically untreated control group.

PL Is Involved with ERK, p38 Kinases, and NF- $k$ B p65 Translocation To elucidate whether mitogen-activated protein kinases (MAPK) were activated by PL and inhibited by corresponding signal pathway inhibitors in our experimental conditions, DC were treated with $100 \mu \mathrm{g} / \mathrm{ml}$ of PL or $100 \mathrm{ng} / \mathrm{ml}$ of LPS (positive control); and activation of ERK and p38 kinases was measured as phosphorylation of the proteins; and the NF- $\kappa \mathrm{B}$ pathway was determined as nuclear translocation of NF- $\kappa \mathrm{B}$ p 65 subunit by Western blot. PL and LPS were found to induce the phosphorylation of ERK1/2 and p38 MAPKs in DC (Fig. 6A). Additionally, both PL and LPS were found to strongly induce the p65 translocation in DC (Fig. 6B). These results show that PL induces the activation of $\mathrm{NF}-\kappa \mathrm{B}, \mathrm{p} 38$, and ERK1/2, which are the downstream effector molecules of the TLR2 and/or TLR4 signal pathways.

To evaluate the effect of ERK and p38 activation on the expression of surface molecules and intracellular IL-12 production in DC, immature DC were treated with a specific MEK 1 inhibitor or p38 inhibitor before PL stimulation. Pretreatment with $30 \mu \mathrm{M}$ of PD98059 (a specific inhibitor of MEK 1; 734 \pm 76 ), SB203580 (a specific inhibitor of p38; $598 \pm 56$ ), and PDTC (an inhibitor of NF- $\kappa$; $658 \pm 37$ ) remarkably inhibited PL-induced up-regulation of the expression of CD86 and MHC class II (Fig. 7A), and the production of intracellular IL-12p40/p70 (Fig. 7B). The results indicate that ERK, p38, and NF- $\kappa \mathrm{B}$ are involved in PL-induced regulation of CD86 and MHC class II; and IL-12 expression in murine DC.

\section{DISCUSSION}

DC are potent antigen-presenting cells with the unique ability to initiate both innate immune responses and antigenspecific adaptive immunity. Therefore, these cells have been the focus of intensive investigations in biomedical research in the area of cancer research for developing DC-based can- 
A
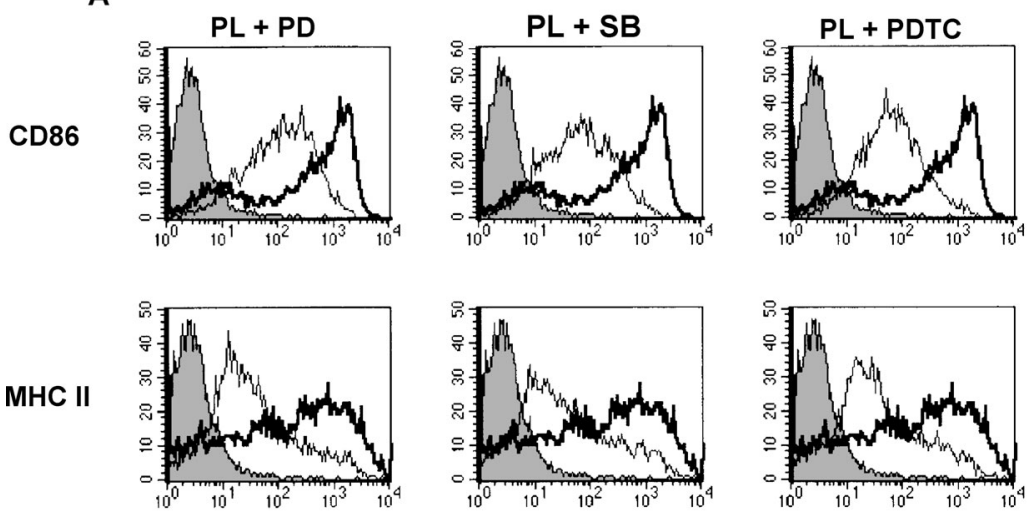

B

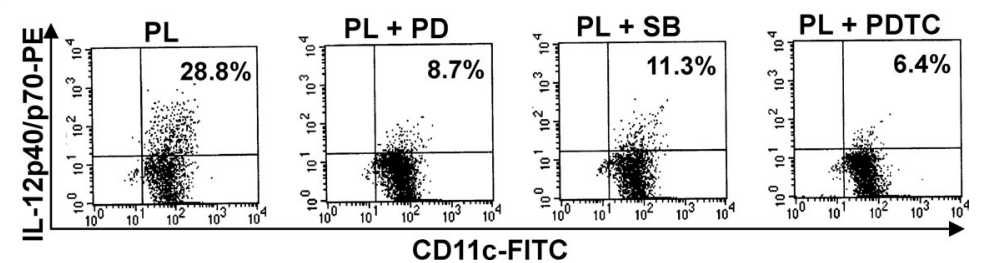

Fig. 7. PL-Induced Up-Regulation of Surface Molecules (CD86 and MHC Class II) and IL-12 Was Inhibited by PD98059 (PD), SB203580 (SB), or PDTC

DC were pretreated with or without PD98059, SB203580, or PDTC for $30 \mathrm{~min}$, and then stimulated with $100 \mu \mathrm{g} / \mathrm{ml}$ for $24 \mathrm{~h}$. Cells were gated on CD11 $\mathrm{c}^{+}$and analyzed the expression of CD86 and MHC class II (A). In parallel experiment, intracellular IL-12p40/p70 expression was subsequently analyzed by flow cytometry (B). Similar results were observed in three independent experiments.

cer vaccines as a novel immunotherapy. ${ }^{1-4)}$ DC activate both naive and memory $\mathrm{CD}^{+}$and $\mathrm{CD}^{+} \mathrm{T}$ cells ${ }^{35-37)}$ and seem to meet all requirements as a strong immune-activator for anti-tumor immunity or immunity against microbial infection. $^{38-40)}$ Located in most host tissues, DC function as immune sentinels for infectious agents and inflammatory products of bacteria. Immature DC can capture antigens in peripheral tissues and undergo maturation processes to stimulate naive $T$ cells in secondary lymphoid organs. The aim of this study was to determine whether PG induces the phenotypic and functional maturation of DC through the TLR signal pathway. The DC stimulated with PL resulted in increased surface expression of CD86 and MHC class II in does-dependent manner. PL also induced the reduction of endocytosis and the enhancement of intracellular IL-12p70, suggesting that PL treatment directly induces DC to mature. PL-treated DC were much more potent antigen-presenting cells in an allogeneic immune response than untreated DC.

Biologically active polysaccharides isolated from Ganoderma and Candida have been shown to induce the phenotypic and functional maturation of murine DC. ${ }^{12,13)}$ However, the molecular basis of the signal transduction pathway activated by these polysaccharides is not fully understood, mainly due to the lack of the identification of specific cellsurface receptors, especially DC. TLRs are a family of proteins that play an essential role in the recognition of invading pathogens and the activation of cytokine production by DC and macrophages. TLRs are sentinel receptors capable of recognizing PRRs and initiating innate immune responses. The members of the TLR family play different roles in PRRs signaling and are not equally expressed on im- mune cells. Further, it has been suggested that different mechanisms may control IL-12 and TNF- $\alpha$ production. ${ }^{41-43)}$ As described before, the stimulation of TLRs leads to the activation of several MAPK pathways, suggesting that TLRs have or share a common signaling pathway. ${ }^{44-46)}$ The activation of a MAPK pathway subsequently induces gene expression by activating several transcription factors, including $\mathrm{NF}-\kappa \mathrm{B}$ and $\mathrm{AP}-1 .{ }^{47)}$ Our results provided evidence for $\mathrm{PG}$ stimulation of murine DC via TLR 2 and/or TLR4 resulting in the activation of MAPK. The roles of ERK and p38 signaling in the TLR pathway induced by PL were investigated. Both ERK and p38 kinases were activated in DC stimulated with PL. Pretreatment with MEK1 or p38 inhibitors suppressed increase of CD86 and MHC class II molecules, and IL-12 production. ${ }^{17,23,27)}$ In support of this, pretreatment of DC with PD98059 (ERK1/2 inhibitors) or SB203580 (p38 inhibitors) decreased CD86 and MHC class II, and IL-12 production. NF- $\kappa \mathrm{B}$ activation is essential for the expression of a variety of cytokines in the proinflammatory cytokine and LPS responses. ${ }^{2327)}$ The reactive oxygen intermediate scavenger PDTC is a potent NF- $\kappa \mathrm{B}$ inhibitor. When used at a dose of $15 \mu \mathrm{M}$, PDTC inhibited PL-induced NF- $\kappa$ B p65 subunit nuclear translocation, as well as the up-regulation of surface molecules (CD86 and MHC class II) and IL-12 secretion, suggesting that the NF- $\kappa \mathrm{B}$ pathway is important in the PL-mediated TLR signaling in DC.

Excessive activation of TLR signaling could be detrimental and lead to tissue injury, including inflammation and autoimmune diseases, such as Crohn's disease and inflammatory bowel diseases. ${ }^{48)}$ Moreover, the administration of LPS to mice can result in the manifestation of septic shock in a 
TLR-4 dependent manner. ${ }^{49,50)}$ However, it is now evident that mammalian TLRs stimulates an innate immune response and increases an adaptive immune response that augments both cell-mediated and humoral immune responses. ${ }^{51)}$ Based on this point of view, it would be possible to exploit the TLR activation pathway, as a means of inducing immune responses, for treatment of infectious disease and cancer. It is intriguing to speculate that mushroom-derived polysaccharides can directly activate innate immune response by mediating TLR signaling, because natural polysaccharides have been safely used as ingredients of traditional medicines for a long period in many oriental countries. Moreover, they have not been associated with any detrimental tissue injuries, which can be caused by LPS, at their biologically effective concentrations. ${ }^{49)}$ This fact allows this polysaccharide to be viewed as a promising candidate ligand of TLRs.

In conclusion, PL enhances the phenotypic and functional maturation of DC via TLR2 and/or TLR 4 pathways. As previously reported, PL has several different immunomodulating activities, including the augmentation of DC maturation. Therefore, it may be speculated that PL augments the antitumor effects of DC-based immunotherapy. We are currently investigating the in vivo anti-tumor effects of combination therapy involving PL and DC in a tumor-bearing mouse model.

Acknowledgements This work was supported by the Korea Science \& Engineering Foundation (KOSEF) through Medical Research Center for Cancer Molecular Therapy at Dong-A University, by Medical Research Institute Grant (2002-01-36) of Pusan National University Hospital, by Pusan National University in the program, Post-Doc. 2004, and Wonkwang University in 2002.

\section{REFERENCES}

1) Banchereau J., Steinman R. M., Nature (London), 392, 245-252 (1998).

2) Steinman R. M., Annu. Rev. Immunol., 9, 271-296 (1991).

3) Rescigno M., Winzler C., Delia D., Mutini C., Lutz M., RicciardiCastagnoli P., J. Leukoc. Biol., 61, 415-421 (1997).

4) Crowley M., Inaba K., Steinman R. M., J. Exp. Med., 172, 383-386 (1990).

5) Rock K. L., Immunol. Today, 17, 131-137 (1996).

6) Austyn J. M., Kupiec-Weglinski J. W., Hankins D. F., Morris P. J., J. Exp. Med., 67, 646-651 (1998).

7) De Smedt T., Pajak B., Muraille E., Lespagnard L., Heinen E., De Baetselier P., Urbain J., Leo O., Moser M., J. Exp. Med., 184, 14131424 (1996).

8) Cella M., Sallusto F., Lanzavecchia A., Curr. Opin. Immunol., 9, 1016 (1997).

9) Salio M., Cerundolo V., Lanzavecchia A., Eur. J. Immunol., 30, 705708 (2000).

10) Kolb-Maurer A., Gentschev I., Fries H. W., Fiedler H. W., Brocker E. B., Kampgen E., Goebel W., Infect. Immun., 68, 3680-3686 (2000).

11) Marovich M. A., McDowell M. A., Thomas E. K., Nutman T. B., J Immunol., 164, 5858-5865 (2000).

12) Cao L. Z., Lin Z. B., Immunol. Lett., 83, 163-169 (2002).

13) Kikuchi T., Ohno N., Ohno T., Int. Immunopharmacol., 2, 1503-1508 (2002).

14) Akira S., Takeda K., Kaisho T., Nature Immunol., 2, 675-680 (2001).

15) Anderson K. V., Curr. Opin. Immunol., 12, 13-19 (2000).

16) Lemaitre B., Nicolas E., Michaut L., Reichhart J. M., Hoffmann J. A. Cell, 86, 973-983 (1996).
17) Aliprantis A. O., Yang R. B., Mark M. R., Suggett S., Devaux B., Radolf J. D., Klimpel G. R., Godowski P., Zychlinsky A., Science, 285 , $736-739$ (1999)

18) Brightbill H. D., Libraty D. H., Krutzik S. R., Yang R. B., Belisle J. T., Bleharski J. R., Maitland M., Norgard M. V., Plevy S. E., Smale S. T., Brennan P. J., Bloom B. R., Godowski P. J., Modlin R. L., Science, 285, 732-736 (1999).

19) Hirschfeld M., Kirschning C. J., Schwandner R., Wesche H., Weis J. H., Wooten R. M., Weis J. J., J. Immunol., 163, 2382-2386 (1999).

20) Takeuchi O., Kaufmann A., Grote K., Kawai T., Hoshino K., Morr M., Muhlradt P. F., Akira S., J. Immunol., 164, 554-557 (2000).

21) Hoshino K., Takeuchi O., Kawai T., Sanjo H., Ogawa T., Takeda Y., Takeda K., Akira S., J. Immunol., 162, 3749-3752 (1999).

22) Arbour N. C., Lorenz E., Schutte B. C., Zabner J., Kline J. N., Jones M., Frees K., Watt J. L., Schwartz D. A., Nat. Genet., 25, 187-191 (2000).

23) Hayashi F., Smith K. D., Ozinsky A., Hawn T. R., Yi E. C., Goodlett D. R., Eng J. K., Akira S., Underhill D. M., Aderem A., Nature (London), 410, 1099-1103 (2001).

24) Tokunaga T., Yamamoto T., Yamamoto S., Jpn. J. Infect. Dis., 52, $1-$ 11 (1999).

25) Krieg A. M., Wagner H., Immunol. Today, 21, 521-526 (2000).

26) May M. J., Ghosh S., Immunol. Today, 19, 80-88 (1998).

27) Yang R. B., Mark M. R., Gurney A. L., Godowski P. J., J. Immunol., 163, 639-643 (1999).

28) Ulevitch R. J., Tobias P. S., Annu. Rev. Immunol., 13, 437-457 (1995).

29) Kim H. M., Han S. B., Oh G. T., Kim Y. H., Hong D. H., Hong N. D., Yoo I. D., Int. J. Immunopharmacol., 18, 295-303 (1996).

30) Kim G. Y., Park S. K., Lee M. K., Lee S. H., Oh Y. H., Kwak J. Y., Yoon S., Lee J. D., Park Y. M., Int. Immumopharmacol., 3, 12811292 (2003).

31) Kim G. Y., Oh Y. H., Park Y. M., Biochem. Biophys. Res. Commun., 309, 399-407 (2003).

32) Han S. B., Lee C. W., Jeon Y. J., Hog N. D., Yoo I. D., Yang K. H., Kim H. M., Immunopharmacol., 41, 157-164 (1999).

33) Kim G. Y., Park H. S., Nam B. H., Lee S. J., Lee J. D., Biores. Technol., 87, 81-87 (2003).

34) Sallusto F., Lanzavecchia A., J. Exp. Med., 179, 1109-1118 (1994).

35) Banchereau J., Briere F., Caux C., Davoust J., Lebecque S., Liu Y. J., Pulendran B., Palucka K., Annu. Rev. Immunol., 18, 767-811 (2000).

36) Lanzavecchia A., Sallusto F., Cell, 106, 263-266 (2001).

37) Liu Y. J., Cell, 106, 259-262 (2001).

38) Chaux P., Favre N., Martin M., Martin F., Int. J. Cancer, 72, 619-624 (1997).

39) Gabrilovich D. I., Corak J., Ciernik I. F., Kavanaugh D., Carbone D. P., Clin. Cancer Res., 3, 483-490 (1997).

40) Troy A. J., Summers K. L., Davidson P. J., Atkinson C. H., Hart D. N., Clin. Cancer Res., 4, 585-593 (1998).

41) Means T. K., Pavlovich R. P., Roca D., Vermeulen M. W., Fenton M. J., J. Leukoc. Biol., 67, 885-893 (2000).

42) Martin M., Michalek S. M., Katz J., Infec. Immun., 71, 2498-2507 (2003).

43) Tapping R. I., Akashi S., Miyake K., Godowski P. J., Tobias P. S., J. Immunol., 165, 5780-5787 (2000).

44) Jones B. W., Heldwein K. A., Means T. K., Saukkonen J. J., Fenton M. J., Ann. Rheu. Dis., 60, 6-12 (2001).

45) Ozinsky A., Underhill D. M., Fontenot J. D., Hajjar A. M., Smith K. D., Wilson C. B., Schroeder L., Aderem A., Proc. Natl. Acad. Sci. U.S.A., 97, 13766-13771 (2000).

46) Re F., Strominger J. L., J. Biol. Chem., 276, 37692-37699 (2001).

47) Ninomiya-Tsuji J., Kishimoto K., Kiyama A., Inoue J., Cao Z., Matsumoto K., Nature (London), 398, 252-256 (1999).

48) Modlin R. L., Ann. Allergy, Asthma, \& Immun., 8, 538-547 (2002).

49) Lehner M. D., Morath S., Michelsen K. S., Schumann R. R., Hartung T., J. Immunol., 166, 5161-5167 (2001).

50) Kobayashi K., Hernandez L. D., Galan J. E., Janeway C. A., Jr., Medzhitov R., Cell, 110, 191-202 (2002).

51) Han S. B., Yoon Y. D., Ahn H. J., Lee H. S., Lee C. W., Yoon W. K. Park S. K., Kim H. M., Int. Immunopharacol., 3, 1301-1312 (2003). 